\title{
O Alquimista
}
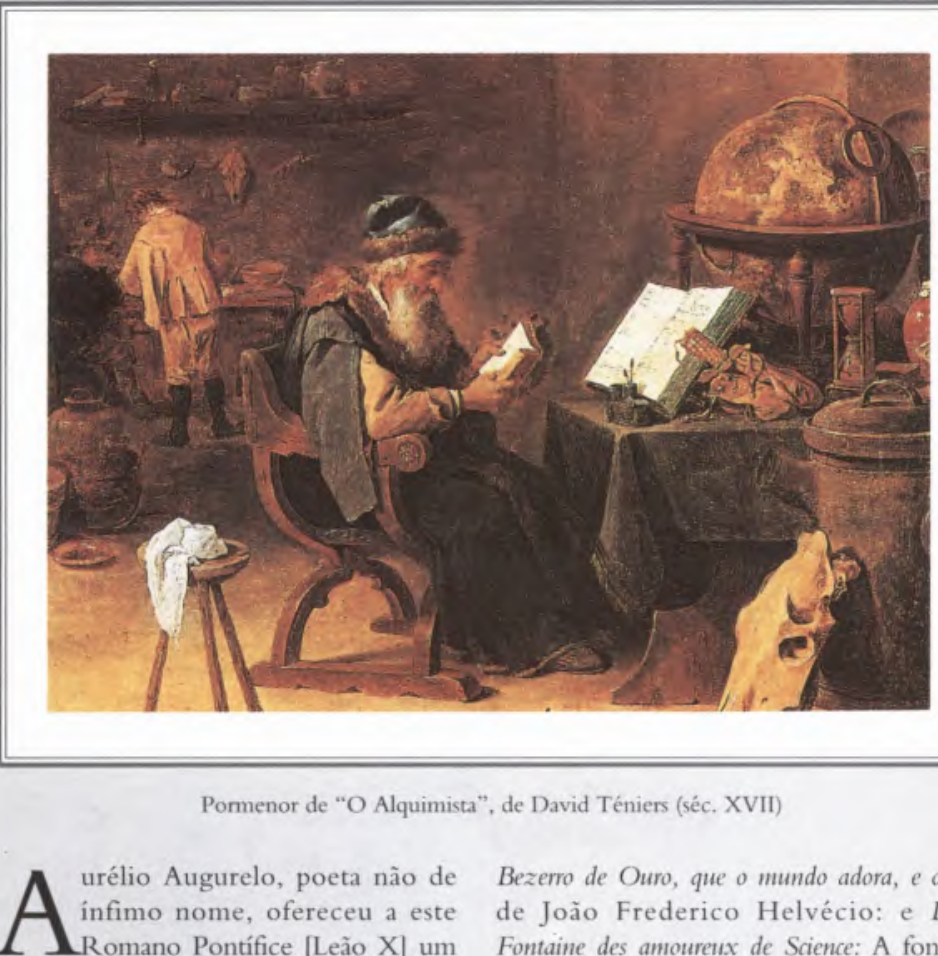

Pormenor de "O Alquimista", de David Téniers (séc. XVII)

A urélio Augurelo, poeta não de infimo nome, ofereceu a este Romano Pontífice [Leão X] um livrinho em verso, em que tratava da Crisopeia, ou Arte aurifatória, que promete e ensina a tirar ouro dos outros metais, por via de operações químicas. $\mathrm{O}$ papa, que não ignorava os embustes dos professores de tal Arte, lhe mandou dar uma bolsa vazia, dizendo: Se é verdade o que promete, basta que lhe dêmos onde guarde o ouro.

Os nomes ou elogios que os químicos dão à Pedra Crisopeia, ou filosofal (que é o mais abstruso mistério de sua Arte, em cujo alcance suam todos eles há muitos séculos), verdadeiramente são magníficos e excitadores de grandes esperanças. Chamam-lhe Céu, Mistério, Crisosperma ou Semente de Ouro, Terra Bendita, Água de Vida, Água Seca, Árvore da Vida, Selo de Salomão, Fogo da Natureza, Leite de Virgem, Mercúrio dos Filósofos, Dragão Águia, Medicamento de todas as Enfermidades, Copo de Pândora, Terra de Promissão, Sagrada Obra da Terra e outros semelhantes. Não são menos arrogantes e especiosos os títulos que põem nos seus livros os autores que desta matéria escrevem. Aqui vereis o Aureum saeculum redivivum de Henrique Madatano, e a Demonstratio Naturae de Mehung; acolá o Summarium Philosophicum de Nicolau Flamel; e o
Bezerro de Ouro, que o mundo adora, e ora de João Frederico Helvécio: e $\mathrm{La}$ Fontaine des amoureux de Science: A fonte dos amantes da Ciência, que compôs João de la Fontaine, ano 1413.

\section{(...)}

A matéria desta Pedra filosofal, convêm os mais doutos que é enxofre e azougue; mas outros, não há coisa vil e imunda que lhe não metam: escória de ferro, cabelos, sapos, cascas de ovos, sangue humano e até o menstro femíneo. Se os efeitos são verdadeiros, ou não, é questão assaz debatida entre os doutores, porque uns afirmam confiadamente que sai ouro, ainda mais perfeito que o natural; e o referido poeta Aurélio Augurelo diz ser tanta a virtude da dita Pedra que

Ipsi ut tenui projecto parte per undas, Aquoris argentum si vinum tum foret aquor, Onne vel immensum verti mare posset in aunim:

A parte dela mínima, lançada No mar, se só azougue o mar tivera Em ouro o mar imenso convertera.

Outros negam, e têm para si que todas as relações e experiências que há pela parte contrária são embustes de químicos ou ilusões da Mágica demoníaca; e eles mesmos, encontrando-se nos preceitos da Arte, se desonram com nomes afrontosos e descobrem as suas trapaças. E
Paracelso, que é um deles, não duvidou escrever que por esta causa tinham sido enforcados só dos seus discípulos vinte e um.

Outros, finalmente, tomam pelo caminho do meio, como mais prudencial, e sentem que é possível, por força da Arte, a dita Crisopeia e sua virtude de transmutar os outros metais em ouro, porém que este ouro é espúrio e análogo, e a experiência mostra não ter todas as qualidades do natural.

De que a este ouro faltam muitas qualidades do natural, sustenta o sapientíssimo padre Atanásio Kirker, que foi um dos mais curiosos e aplicados indagadores da natureza que conheceu o século passado, o qual afirma, e prova, que esta tal pedra filosofal é um mero embuste, e que o que os antigos chamaram assim não é o que os alquimistas agora pretendem; mas concede que se pode fazer ouro adulterino, o qual provado muitas vezes no fogo, descobre enfim sua falsidade.

(...)

E, se o ouro que fazem os verdadeiros alquimistas, levados do amor da ciência, ainda assim não é verdadeiro, qual será o que fazem os demais embusteiros, levados da avareza? A turba destes é inumerável, dos quais dizem discretamẹnte Caetano, que o seu ouro pára em fumo, e Pineda, que: $\mathrm{Hoc}$ non est aunum coquere, sed decoquere; e ordinariamente dão em ladrões e falsificadores de moeda, e invocadores e pactários do demónio, para que os ajude na obra que eles tanto desejam e nunca alcançam. Mas até o mesmo demónio faz escárnio deles, de que traz um gracioso caso Bodino, que refere como a uns alquimistas franceses

Grande torrão de ouro nativo (Brasil, 1732) com 20,4 kg (Palácio Nacional da Ajuda, Lisboa)

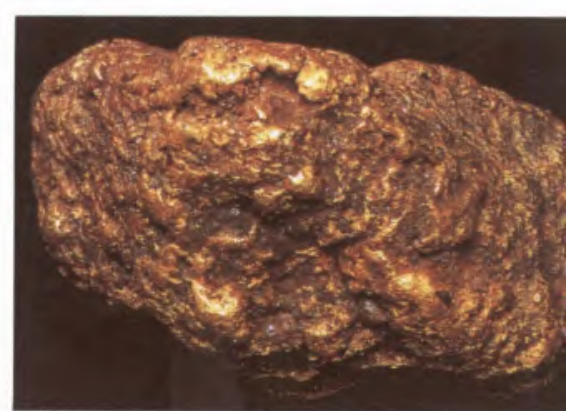


thes entornou e os borrifou o demónio com os mesmos metais derretidos que ele thes ensinara, dando juntamente uma grande risada. E, fazendo-lhe eles queixa do agravo, que não esperavam de seu familiar, e nova instância que se dignasse de thes ensinar a verdade, respondeu: Travaillez; hardiment: Trabalhai animosamente. Com que, os tornou a deixar metidos na sua ilusão. $\mathrm{E}$ aqui se mostra verificado que a sede insaciável dos avarentos até dentro dos infernos vai gostosamente buscar ouro.

Outro caso peregrino, em que se mostra $\mathrm{o}$ ardil com que estes embusteiros encravam os que crêem neles, refere Gomes à Medis, e dele o citado Martin Del-Rio Ljesuíta catedrático em Salamanca], cuja substância é a seguinte: Nos anos passados (diz ele) em Paris um escolar, homem de meia-idade, mui versado nas ciências, e particularmente na química, que, não obstante o embaraço dos seus negócios, folgava de a exercitar ocultamente, e o seu engenho era astutíssimo para fingir, a sua lábia mui apta para persuadir. Neste tempo, em que havia guerras entre o imperador Carlos $\mathrm{V}$ e el-rei Francisco, de França, a quem era mui aceito, se passou por causa de seus negócios a Lovaina, e depois deu consigo em Antuérpia, onde se meteu com quatro mercadores ricos espanhóis, porque sabia a língua destramente. $\mathrm{E}$, vindo-se um dia a falar dos empregos de cada um, e dos avanços, perigos e quebras dos cabedais, ele, sorrindo-se falsamente, disse: Vós outros mesmos tendes a culpa, pois não quereis tomar pelo caminho mais breve, mais seguro e mais lucroso. Que caminho é esse? perguntaram os mercadores. Porventura (respondeu o embusteiro) não é bom o trato em que, sem pôr o meu pé fora de casa nem uma só tábua sobre o mar, peço sem dúvida alguma a olhos vistos avanços cento por cento? Que trato é esse? (replicaram os mercadores). Vós estais zombando. Não zombo (acudiu este, fingindo-se meio colérico, para abandonar o siso com que falava) e pouco disse, em os avanços, eram de cento por cento: pois, se o engenho se aplica, bem pode dar duzentos ou trezentos por cento. Homem (dizem eles, mui atiçados do desejo de ter), declarai-nos esse segredo, por vossa vida. Respondeu, levando-os pouco e pouco ao precipício que pretendia. Dai-me, vós outros, palavra de o não comunicar a pessoa viva. Sim, damos; que segredo é esse? Então, como quem descobre a misteriosa cortina de Apolo Délfico: É (disse) a celebrada, mas igual- mente perseguida Arte aurifatória. E não quero esperar a que me argumenteis, nem oponhais dúvidas; de uma vez fecho a porta a todas, remetendo-me à experiência, que me ofereço fazer diante de vossos olhos, cada vez que quiserdes; e, conforme as quantidades, que me derdes para meter no fogo, assim vereis proporcionada a multiplicação delas. Já os mercadores estavam encravados no engano, nem lhes ocorria dúvida alguma fundamental que perdesse a oferta tão ingénua, patente e desinteressada. Ajuntaram logo entre si quinze dobrões, que foram os que ele disse que bastavam para a primeira mostra. $\mathrm{O}$ qual chamou logo um criado de um dos mesmos mercadores, e, metendo-lthe na mão dois reais, disse mui esperto: Vai ali a qualquer boticário, e pede a pedra Onastro, e, se não houver troco, deixa todos os dois reais, por não esperarmos mais, e traz depressa. E já o criado estava na porta, quando tornou a chamá-lo, dizendo: Ouves tu? 'Vai direito à botica defronte da porta da Sé, que ontem vi vender ai destas pedras, melhores que em qualquer parte. E é de saber que o embusteiro tinha de antemão vazado a quantidade de ouro, que determinava fundir com os quinze dobrões e feito dela uma massa em forma de pedra, pintada fortemente com tintas pegadas com fogo, a qual entregou ao boticário, concertando com ele bem pago, como determinava mandá-la buscar, e que não duvidasse vendê-la barata, porque assim convinha. $\mathrm{E}$ até o nome da pedra malicio eu que continha irrisão dissimulada, porque Onos em grego quer dizer asno, e a partícula Aster entre os latinos bem se sabe que é aumentativa para a parte deterior, como se vê em Oleaster de Olea, Mentaster de Menta, etc., com que a pedra Onastro vinha a ser o mesmo que a pedra Asneirão. Trouxe, pois, o criado a dita pedra, que por ela estava esperando: fecham-se todos na oficina do alquimista mais retirada. Começa ele a lavar a pedra; e os mercadores, pegando dela, ora um ora outro, todos se admiravam; este dizia: Como é pesada para tâo pequena! Aquele: Como é lustrosa, e com galantes veias! Outro respondia: $\mathrm{O}$ que the eu gabo mais é custar tão barata, mas é que the não conhecem as propriedades.

Entretanto a fornalha já estava acesa, e os vasos e instrumentos preparados. O alquimista, mui destro e ágil, punha e dispunha aqui e acolá as coisas necessárias, que todas vinham a ser supérfluas. Pega logo dos quinze dobrōes, que eram a raiz quadrada da multiplicação prometida; começa-os a morder; mete-os

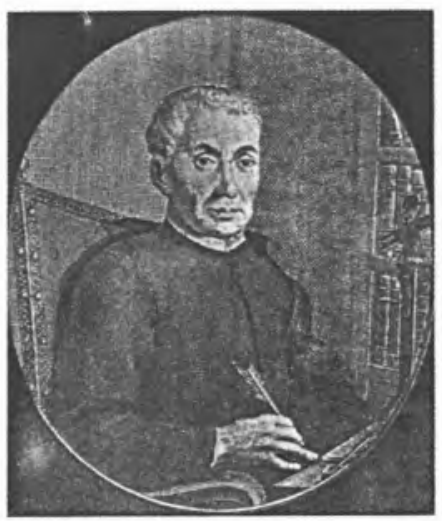

Padre Manuel Bernardes (1644-1710)

debaixo do martelo, murmurando, a trechos, certas palavras, quando os ia espalmando; lança-os a fundir, juntamente com a pedra "Asneirão". Os olhos de todos estavam lá na obra não só postos mas como pregados uniformemente.

Separou o fogo as tintas da pedra e tudo o mais que se tinha misturado; e, finalmente, saiu de ouro a quantidade verdadeira, que se tinha lançado; mas, ao parecer dos mercadores, tresdobrada. Mandou logo o alquimista que dois deles fossem examiná-la ao contraste; e, achando-se ser ouro sem liga alguma, e de toda a conta, voltaram contentíssimos; e, dando aos outros as novas, tal foi a exultação de todos que parecia não caberem em si de gozo. Assim, às portas fechadas, se juramentaram logo de não revelar o mistério da pedra "Asneirão" a pessoa viva. Seguiu-se o dar as graças ao alquimista por tào sinalado benefício, e o repartir com ele do ouro que saíra, e o rogar-lhe repetisse a experiência em qualquer dos seguintes dias, entrando cada um com mil moedas e oferecendo entrar com mais no terceiro lanço. Com efeito, veio à sua mão a dita quantidade, pedindo ele demora só de um dia, para prevenir maiores vasos. E naquela noite montou em cavalos à ligeira para França, levando as quatro mil moedas; e pela manhã não acharam os mercadores mais que os troços e destroços da oficina, cova daquele melhor Caco, e nas suas bolsas os que causara não tanto a pedra Onastro quanto a sua credulidade néscia e cobiça desmoderada.

Padre Manuel Bernardes in Nova Floresta (vol. IV) 